\title{
Development of Abaca Fiber-reinforced Foamed Fly Ash Geopolymer
}

\author{
Ngo, Janne Pauline S. ${ }^{1 *}$, Promentilla, Michael Angelo B. ${ }^{1,2}$ \\ ${ }^{1}$ Chemical Engineering Department, De La Salle University, Manila 0922, Philippines \\ ${ }^{2}$ National Research Council of the Philippines, Taguig, Metro Manila 1631, Philippines
}

\begin{abstract}
The growing environmental and economic concerns have led to the need for more sustainable construction materials. The development of foamed geopolymer combines the benefit of reduced environmental footprint and attractive properties of geopolymer technology with foam concrete's advantages of being lightweight, insulating and energy-saving. In this study, alkali-treated abaca fiber-reinforced geopolymer composites foamed with $\mathrm{H}_{2} \mathrm{O}_{2}$ were developed using fly ash as the geopolymer precursor. The effects of abaca fiber loading, foaming agent dosage, and curing temperature on mechanical strength were evaluated using Box-Behken design of experiment with three points replicated. Volumetric weight of samples ranged from $1966 \mathrm{~kg} / \mathrm{m}^{3}$ to $2249 \mathrm{~kg} / \mathrm{m}^{3}$. Measured compressive strength and flexural ranged from 19.56 MPa to $36.84 \mathrm{MPa}$, and 2.41 MPa to $6.25 \mathrm{MPa}$, respectively. Results suggest enhancement of compressive strength by abaca reinforcement and elevated temperature curing. Results, however, indicate a strong interaction between curing temperature and foaming agent dosage, which observably caused the composite's compressive strength to decline when simultaneously set at high levels. Foaming agent dosage was the only factor detected to significantly affect flexural strength.
\end{abstract}

\section{Introduction}

Sustainability has been an important drive for research for the past years. Increasing consumptions of resources and materials, as well as the immoderately massive generation of waste, has pulled the research and development of modern materials towards greener alternatives. An important factor to consider is the construction industry to which over $40 \%$ of the global energy consumption and excessively high quantity of carbon dioxide emission is due [1]. This sector has nonetheless seen growth in demand continually and inevitably. Hence, the development of sustainable construction materials to possibly substitute these commodities and reduce environmental footprint should be sought after. Considering this, one of the most promising and fast-growing research in the past two decades is on geopolymer. Geopolymer, an inorganic binder formed by alkaline activation of solid aluminaand silica-containing materials which are often sourced from industrial waste, has emerged as a potential concrete binder - an alternative to ordinary Portland cement (OPC). Geopolymer production is reported to curb $\mathrm{CO}_{2}$ emission of traditional cement clinker by 60 to $80 \%$ [2]. Moreover, it finds increasing applications in other areas due to its unique properties such as thermal and fire resistance.
Previous studies have reported foamed concrete's brittleness to be unsuitable for bending and squash loads [3]. Fiber reinforcement is commonly employed to enhance mechanical strength by allowing load transfer and crack bridging. Commonly reinforced fibers in cementitious materials include steel and polymeric fibers [4]. The use of natural fiber has recently been explored, particularly for its inherent mechanical properties, low density, low cost, abundance and biodegradability.

\subsection{Abaca Fiber}

Abaca fiber which is native and abundant in the Philippines is widely used for its commendable mechanical properties and utility for polymer reinforcement. An annual report in 2015 reveals that 70,400 metric tons of the fiber was produced [5].The large volume of harvested high-grade abaca in turn generates a considerable amount of waste or low-grade fibers [6]. As much as three quarters of the abaca is considered agricultural waste and left in plantations to wither after the high-grade fiber is harvested [7]. About 328.5 million kilograms of abaca waste was reported to be generated annually in 2014 . The industry, however, is foreseen to grow even more in the succeeding years. In 2015 , it was reported that the outbound shipments of abaca rose by $39.8 \%$ from the previous year [8]. In 2016,

Corresponding authors: janne_ngo@dlsu.edu.ph; michael.promentilla@dlsu.edu.ph 
farmers have increased their production of abaca by $5.7 \%$ (from 58,665.8 MT to 62,008.6 MT) from the previous year to meet the demand for the crop in the Philippine's export market [9]. It was reported in 2015 that the about $87.7 \%$ of the profit gained from abaca came from finished goods such as fabrics, cordage and fiber crafts, while raw abaca fibers accounted for the remaining exports. However, revenue from raw abaca fiber has been tripling year after year [8]. Raw abaca fiber's application in various industries has indeed broadened. As of present, the most common innovative use of abaca-reinforced composites has been in underfloor protection of automotive [10]. With the high volume of agricultural waste involved in this growing industry, it would therefore be advantageous for the environment if these wastes or scrap fibers can be treated and utilized in advanced materials. With that said, this study aims to explore the use of waste abaca fiber as reinforcement in geopolymer with foaming. Particularly, this study aims to develop an abaca-reinforced fly ash geopolymer foamed with hydrogen peroxide $\left(\mathrm{H}_{2} \mathrm{O}_{2}\right)$ and to assess its compressive and flexural strength under various fiber loading, $\mathrm{H}_{2} \mathrm{O}_{2}$ dosage and curing temperature.

\subsection{Fiber Pretreatment}

Often, reinforcement is employed in order to improve the material's mechanical properties. Fibers are used as load-bearing materials imbedded in another's matrix, thus providing rigidity, strength and flexibility in many cases [4]. The resulting junction is called a composite. Concrete is often reinforced to address premature cracking that develop with shrinkage during the hardening of the paste. This shrinkage, called plastic shrinkage, occurs due to loss of moisture [11]. Fiber reinforcement has been effective preventing crack propagation by bridging cracks and by allowing load transfer. However in some cases, fiber loading can be counterproductive and lead to compressive strength reduction due to factors like improper distribution and weak interfacial interaction. When the fiber acts more as an interference in the matrix than an aid or reinforcement, mechanical properties may become less desirable [11-12].

Stress sharing and transfer between the fiber and the matrix depend on fibre-fibre and fibre-matrix adhesion and interactions. Effective reinforcement relies on compatibility of components. Likewise, incompatibility may only result to decline in mechanical strength and promote deterioration. This has been reported by prior studies to be a disadvantage of natural fibers. Natural fibers typically consist of lignin, pectin, cellulose, hemicellulose, moisture and other compounds such as fats and waxes. It is basically a composite in itself of polymers: cellulose, hemicellulose and lignin [13]. Due to its hydrophilic nature and thus, tendency for water absorption, natural fibers may exhibit weak interfacial bonding with hydrophobic matrix [12, 14-17]. This is often observed in polymer composites. Furthermore, 'swelling' may occur when a hydrophilic fiber within a hydrophobic resin absorbs moisture, making it susceptible to weakening and even deterioration [18]. Consequently, softened fibers will result to reduced strength.

The most economical and well-studied treatment to overcome this disadvantage is alkali treatment [16]. Soaking fibers in alkali solution, commonly sodium hydroxide $(\mathrm{NaOH})$, strips them of impurities which contribute to water absorption and incompatibility. Parts of the amorphous components lignin, hemicellulose and pectin are removed, resulting to smaller fibers with increased effective surface area. The remaining fiber after these components come off will reveal a rough surface, thereby increasing the fiber's resistance to being pulled out of the matrix [16].

\section{Methodology}

In this study, alkali-pretreatment was performed on the waste abaca as follows: fibers were initially cut to approximately $1 \mathrm{~cm}$ strands. A solution of $6 \mathrm{wt} \% \mathrm{NaOH}$ was prepared from $12 \mathrm{M} \mathrm{NaOH}$ available. The waste abaca fibers were then submerged in the alkali solution following the proportion 70-80 mg fiber per $100 \mathrm{~mL}$ solution for 2 hours. The fibers were subsequently washed with water until they are sufficiently neutralized to about $\mathrm{pH}$ 7. Then, the fibers were air-dried for 24 hours. This procedure was reported to yield the best mechanical strength improvement of abaca reinforced in epoxy [17]. Fig. 1 shows the untreated and treated abaca fibers.

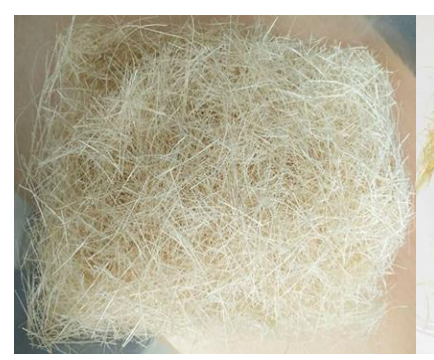

(a)

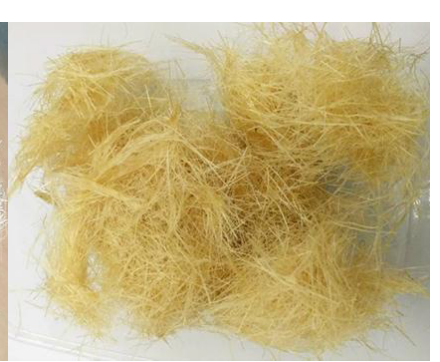

(b)
Fig. 1. (a) Untreated and (b) treated abaca fibers

Preparation of geopolymer composites consists of two parts: (1) preparation of alkali activator solution and (2) preparation of the composites. For the alkali activator solution, waterglass to sodium hydroxide solution (WGS/NaOH) was fixed at mass ratio 1.66. The activator solution was mixed thoroughly with a magnetic stirrer. After 15 minutes, $50 \mathrm{wt} \%$ hydrogen peroxide was added at $0.16,0.24$ and 0.32 weight $\%$ of the fly ash used to the activator solution and mixed for 5 more minutes.

To prepare the specimen with fiber reinforcement, the cut, treated and dried abaca fibers were dry-mixed with sieved fly ash (2mm) to ensure uniform distribution. Fiber loading was designated to $0 \%, 0.25 \%$ and $0.5 \mathrm{wt} \%$ of the weight of fly ash used. Meanwhile, the prepared alkali activator was incorporated with the fly ash and 
abaca following mass ratio $\mathrm{NaOH} / \mathrm{FA}=0.2$. The slurry was manually mixed first to ensure the desired consistency. Then, the mixture was thoroughly mixed in a mechanical mixer for about 15 minutes until fiber strands were well-distributed and that homogeneity was achieved. The geopolymer paste was then casted on moulds, allowed to dry for 24 hours and removed from the moulds. Samples were then placed in air-tight plastics and cured at various temperatures, $30^{\circ} \mathrm{C}, 52.5^{\circ} \mathrm{C}$ and $75^{\circ} \mathrm{C}$, for 2 hours, followed by 24 -hour hardening at room temperature.

Scanning electron microscopy (SEM) images of treated and untreated abaca fibers were taken and analysed. Thermal gravimetric analyses were also performed on the fibers. Subsequently, the prepared geopolymer composites were characterized by SEM image analysis, volumetric weight and water absorption. Finally, compressive strength and flexural strengths of the composites were measured.

\section{Results and Discussion}

\subsection{Scanning electron microscopy analysis of abaca}

(SEM)

Scanning electron microscopic image analyses were carried out using Field-emission scanning electron microscope (FESEM Dual Beam Helios Nanolab 600i) equipped with electron-dispersive X-ray spectroscopy. Images were taken at accelerating voltage $=2.0 \mathrm{kV}$ and beam current $=43 \mathrm{pA}$. SEM images of the fiber samples at 500x and 5000x magnification are presented in Fig. 2. Fig. 2a and Fig. 2c shows the untreated fiber whose surface evidently has less uniformity. "Impurities" which could likely be the weak and dislodged hemicellulose are visible. It is observed in Fig. 2b and Fig. 2d that these impurities were stripped off, revealing a more uniform but rougher surface. After treatment, corrugation on the fiber surface was observed. Corrugation and roughening of the surface indicate a better fiber-matrix interface by virtue of mechanical interlocking. This surface modification indicates higher frictional bond between the two components, which has previously shown to be effective in resisting shear and bending stress

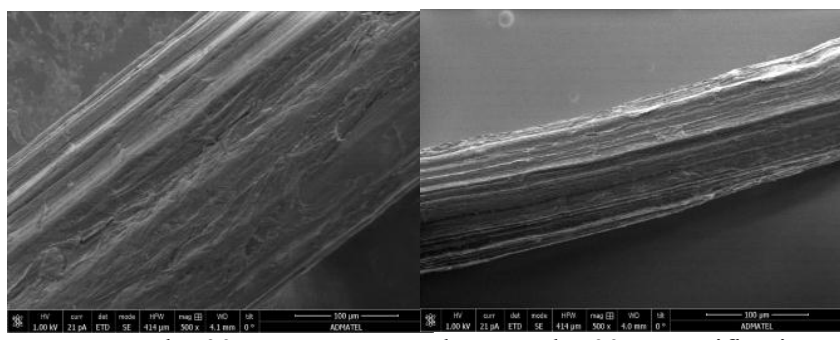

a. untreated, 500x

b. treated, 500x magnification

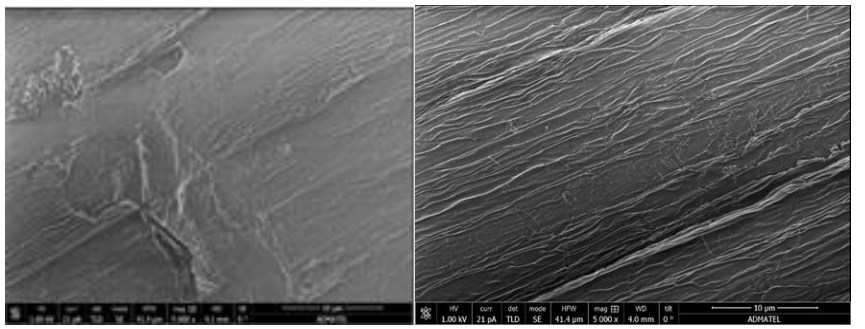

c. untreated, $500 \mathrm{x}$

d. treated, 500x magnification magnification

Fig. 2. SEM images of waste abaca before and after treatment

\subsection{Thermogravimetric analysis (TGA) of abaca}

Percent mass loss during the ramp increase in temperature was analyzed using TGA. This analysis allows evaluation of the fiber's composition. According to previous studies, cellulosic fibers' thermal decomposition commonly comprises of loss of moisture, degradation of hemicellulose, cellulose and lignin. Table 1 summarizes this with each component's degradation temperature [19].

Table 1. Decomposition Temperatures of Natural Fibers' Components.

\begin{tabular}{|c|l|c|}
\hline Components & $\begin{array}{l}\text { Decomposition } \\
\text { Temp, }{ }^{\circ} \mathrm{C}\end{array}$ & $\mathrm{T}_{\max },{ }^{\circ} \mathrm{C}$ \\
\hline Moisture & $30-100$ & 80 \\
\hline Hemicellulose & $160-350$ & $245-298$ \\
\hline Cellulose & $240-365$ & 335 \\
\hline Lignin & $300-500$ & 337 \\
\hline
\end{tabular}

Fig. 3 shows the thermograms of both the untreated (a) and treated (b) abaca samples. Meanwhile, Table 2 summarizes the observed thermal degradation of the untreated and treated abaca samples. $\mathrm{T}_{\max }$ is defined as the temperature at which the fastest rate of degradation was observed, and it was taken using differential thermogravimetry (DTG). The first stage of decomposition primarily removed free and absorbed moisture from the abaca fibers. For the untreated fiber, decomposition observed between $200^{\circ} \mathrm{C}$ and $370^{\circ} \mathrm{C}$ resulted to a mass loss equivalent to $78.2 \%$. $\mathrm{T}_{\max }$ was observed at $345^{\circ} \mathrm{C}$ wherein the maximum rate of decomposition was $1.1 \%$ per ${ }^{\circ} \mathrm{C}$. This is mainly accounted to the decomposition of hemicellulose. At the same decomposition stage, the treated fiber experienced a lower \% mass loss $(71.2 \%)$, which indicates its lower hemicellulose content. Beyond this is the onset of the decomposition of cellulose and lignin. This was allowed to proceed up to $900^{\circ} \mathrm{C}$, where $87.1 \%$ and $79.0 \%$ were the measured mass losses for the untreated and treated fiber samples, respectively. This signifies that the treated samples contained lower combined cellulose and lignin content. The untreated fiber's residual mass was $12.9 \%$ while that of the treated sample was $21 \%$. These results 
signify that the treatment was able to remove the weak and dislodged components off of the abaca fiber.

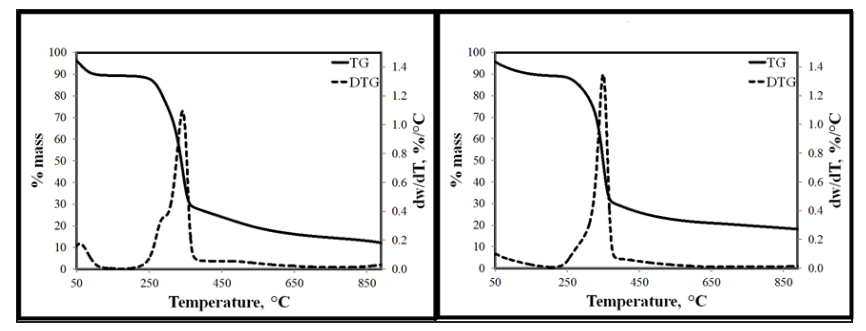

Fig. 3. Thermograms of (a) untreated and (b) treated abaca

Table 2. Observed Decomposition Stages of Abaca Samples

\begin{tabular}{|r|l|l|l|l|l|l|l|}
\hline fiber & \multicolumn{3}{|l|}{ Decomposition 1 } & \multicolumn{3}{l|}{ Decomposition 2 } & $\begin{array}{l}\% \\
\text { mass } \\
\end{array}$ \\
\cline { 2 - 7 } & $\begin{array}{l}\mathrm{T}_{\max } \\
{ }^{\circ} \mathrm{C}\end{array}$ & $\begin{array}{l}\% \\
\text { mass } \\
\operatorname{loss}\end{array}$ & $\begin{array}{l}\text { Rate, } \\
\% /{ }^{\circ} \mathrm{C}\end{array}$ & $\begin{array}{l}\mathrm{T}_{\max } \\
{ }^{\circ} \mathrm{C}\end{array}$ & $\begin{array}{l}\% \\
\text { mass } \\
\text { loss }\end{array}$ & $\begin{array}{l}\text { Rate, } \\
\% /{ }^{\circ} \mathrm{C}\end{array}$ & $\begin{array}{l}\text { up } \\
900^{\circ} \mathrm{C}\end{array}$ \\
\hline Raw & 62 & 8.9 & 0.3 & 345 & 78.2 & 1.1 & 87.1 \\
\hline Treated & 53 & 7.8 & 0.1 & 350 & 71.2 & 1.3 & 79.0 \\
\hline
\end{tabular}

\subsection{Density and water absorption of geopolymer composites}

The resulting volumetric weight of each treatment was taken as the average of three cubic samples from each run. Each sample's dimensions were measured using caliper and weighed subsequently. Pristine geopolymer samples $\left(0 \%\right.$ fiber loading, $0 \% \mathrm{H}_{2} \mathrm{O}_{2}$ dosage, cured at $52.5^{\circ} \mathrm{C}$ ) were measured to have a mean $2149.1 \mathrm{~kg} / \mathrm{m}^{3}$ volumetric weight. The resulting volumetric weights of the samples ranged from $1966.38 \mathrm{~kg} / \mathrm{m}^{3}$ to $2249.52 \mathrm{~kg} / \mathrm{m}^{3}$. The mean is $2099.687 \mathrm{~kg} / \mathrm{m}^{3}$. The average value for the foamed samples is relatively high compared to that of a typical foam concrete whose volumetric weight are at most $1000 \mathrm{~kg} / \mathrm{m}^{3}[20]$. Since the abaca fiber's density is significantly lower than that of fly ash and other raw materials, it is reasonable for the composite's volumetric weight to decrease with abaca loading. Likewise, increasing the foaming agent dosage reduced the volumetric weight due to formation of void spaces within the composite. Increasing the curing temperature also resulted to lower volumetric weight which could be due to higher moisture loss during curing.

Water absorption was measured following ASTM D570. The mass of a cubic sample from each run was measured. The samples were then submerged in distilled water for 24 hours, wiped dry at the surface before being weighed again. Volume changes were observably negligible throughout the experimental procedure. The mass percent moisture absorbed is taken as the water absorption, computed using Eq. 1.

$$
W A=\frac{W_{s a t}-W_{d r y}}{W_{d r y}} \times 100
$$

where $W A=$ water absorption; $W_{\text {sat }}=$ mass at saturated state $; W_{d r y}=$ mass at dry state

The pristine geopolymer sample's measured water absorption value was $4.499 \%$. The values ranged from $3.3821 \%$ to $13.9730 \%$ with a mean value of $6.6228 \%$. The values measured for the experimental samples are found to be in the same range as reports on hardened OPC composites, which can range between $2-15 \%$. A study of coir fiber-reinforced epoxy reported that higher fiber content resulted to increased water absorption due to the present hydroxyl groups [21]. In this study, however, the effect of the fiber loading was statistically insignificant to the composite's water absorption. This is favorable since one of the main concerns of natural fiber reinforcement is the tendency for the organic fiber to draw water in due to its hydrophilic nature. The lack of significance of fiber loading effect to water absorption in this study suggests that the alkali treatment has sufficiently reduced the hydrophilic components in the fiber.

Measured volumetric weight and water absorption are summarized in Table 3.

Table 3. Volumetric weight and water absorption of composites

\begin{tabular}{|l|l|l|l|l|}
\hline $\begin{array}{l}\text { Fiber } \\
\text { Loading } \\
(\%)\end{array}$ & $\begin{array}{l}\mathrm{H}_{2} \mathrm{O}_{2} \\
\text { Dosage } \\
(\%)\end{array}$ & $\begin{array}{l}\text { Curing } \\
\text { Temp. } \\
\left({ }^{\circ} \mathrm{C}\right)\end{array}$ & $\begin{array}{l}\text { Volumetric } \\
\text { Weight } \\
\left(\mathrm{kg} / \mathrm{m}^{3}\right)\end{array}$ & $\begin{array}{l}\text { Water } \\
\text { Absorption } \\
(\%)\end{array}$ \\
\hline 0 & 0.16 & 52.5 & 2249.52 & 4.26 \\
\hline 0 & 0.32 & 52.5 & 2063.17 & 7.18 \\
\hline 0 & 0.24 & 30 & 2178.76 & 13.97 \\
\hline 0 & 0.24 & 75 & 2142.64 & 5.68 \\
\hline 0.25 & 0.16 & 30 & 2155.76 & 8.95 \\
\hline 0.25 & 0.16 & 75 & 2066.80 & 5.53 \\
\hline 0.25 & 0.32 & 30 & 1986.12 & 5.25 \\
\hline 0.25 & 0.32 & 75 & 2016.05 & 4.94 \\
\hline 0.25 & 0.24 & 52.5 & 2190.26 & 3.26 \\
\hline 0.5 & 0.16 & 52.5 & 2179.78 & 6.86 \\
\hline 0.5 & 0.32 & 52.5 & 1966.38 & 7.09 \\
\hline 0.5 & 0.24 & 30 & 2129.43 & 6.33 \\
\hline 0.5 & 0.24 & 75 & 1976.08 & 6.78 \\
\hline
\end{tabular}




\subsection{Scanning electron microscopy (SEM) analysis of geopolymer composites}

SEM images of selected samples at 2000x magnification are shown in Fig. 4.

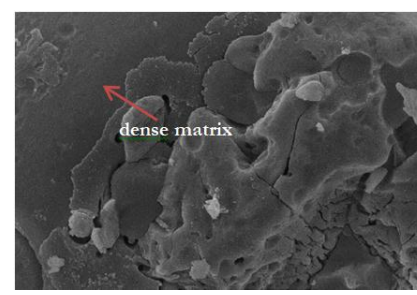

(a) control: $0 \%$ fiber, $0 \%$ $\mathrm{H} 2 \mathrm{O} 2$, cured at $52.5^{\circ} \mathrm{C}$

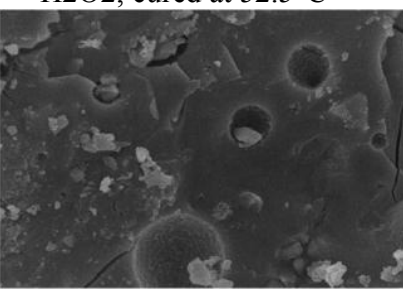

(c) $0.25 \%$ fiber, $0.32 \%$ $\mathrm{H} 2 \mathrm{O} 2$, cured at $75^{\circ} \mathrm{C}$

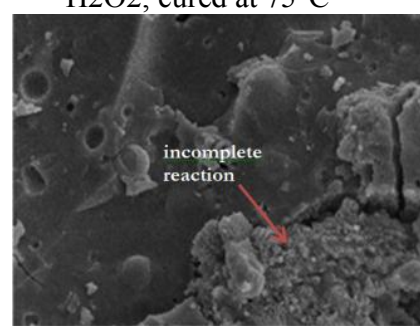

(e) $0.25 \%$ fiber, $0.16 \%$ $\mathrm{H} 2 \mathrm{O} 2$, cured at $30^{\circ} \mathrm{C}$

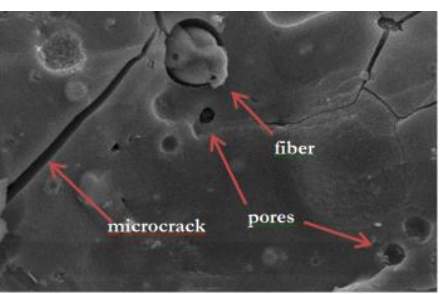

(b) $0.5 \%$ fiber, $0.32 \% \mathrm{H} 2 \mathrm{O} 2$, cured at $52.5^{\circ} \mathrm{C}$

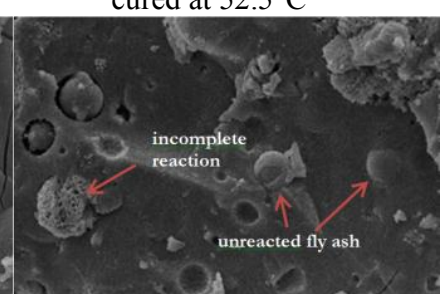

(d) $0.25 \%$ fiber, $0.32 \% \mathrm{H} 2 \mathrm{O} 2$, cured at $30^{\circ} \mathrm{C}$

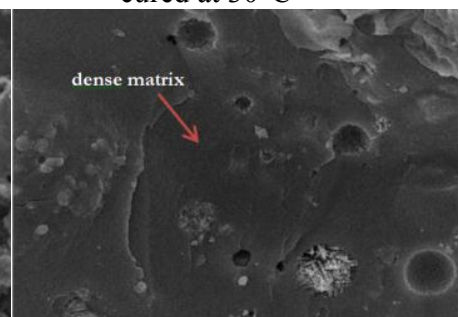

(f) $0.25 \%$ fiber, $0.16 \% \mathrm{H} 2 \mathrm{O} 2$, cured at $75^{\circ} \mathrm{C}$
Fig. 4. SEM Images of geopolymer composites

SEM analysis can provide clues and qualitative validation of premises about the water absorption, and provide later on, the mechanical properties and thermal properties of the composite samples. Unreacted fly ash and incomplete reactions were observed largely in samples that were cured at low temperature as shown in Fig. 4d and Fig. 4e. Samples cured at higher temperatures formed more dense matrices, exhibiting less unreacted fly ash and incomplete reactions. Pores were visibly bigger and more evenly distributed in Fig. 4c and Fig. 4f which were cured at $75^{\circ} \mathrm{C}$. Microcracks were also observed in most of the samples but were more evident in Fig. 4b and Fig. 4c. It can be observed in Figure $5.4 \mathrm{~b}$ that the fiber-matrix gap seemed to have been the site for microcrack formation. In Fig. 4d, in which the sample was cured at low temperature, microcracks were not present along the abaca fibers. This verifies the premise that microcracks tend to form at high fiber loading and high curing temperature. Curing at low temperature, however, can result to incomplete reaction [22], as evidenced by Fig. 4d which shows more unreacted fly ash and less dense matrix. This can translate to lower strength, as well. Microcracks present in Fig. 4c could be due to the high $\mathrm{H}_{2} \mathrm{O}_{2}$ dosage and high curing temperature.

\subsection{Mechanical properties of geopolymer composite}

UNIFRAME stand-alone universal compression/flexural tester was used to measure the compressive and flexural strength of the samples. Compressive strength test was performed following ASTM C109. Meanwhile, the three-point flexural test (ASTM C348) was performed to calculate for the flexural strength of the composites.

\subsubsection{Compressive strength of geopolymer composites}

Compressive strength is a measure of the structure's resistance or ability to withstand compression stress. This parameter, which will be considered as a response in the experiment, is a key mechanical property for construction materials. Standard values of materials acceptable for use as structural 'residential concrete' are at least $17 \mathrm{MPa}$. Moreover, $28 \mathrm{MPa}$ is the minimum compressive strength for materials finding application as commercial structures [23]. 50mm cubic samples were prepared, cured for 28 days and tested for compressive strength. In addition to the 13 treatments, a pristine geopolymer sample and 3 replicated treatments were prepared for the test. Samples were subjected to gradual load with rate $0.4 \mathrm{MPa} / \mathrm{s}$. The maximum loads were recorded at failure. Three replicates were tested for each treatment. The mean ultimate load of the three replicates was taken as the compressive strength for each treatment. Fig. 5 shows the set up for the compressive strength test.

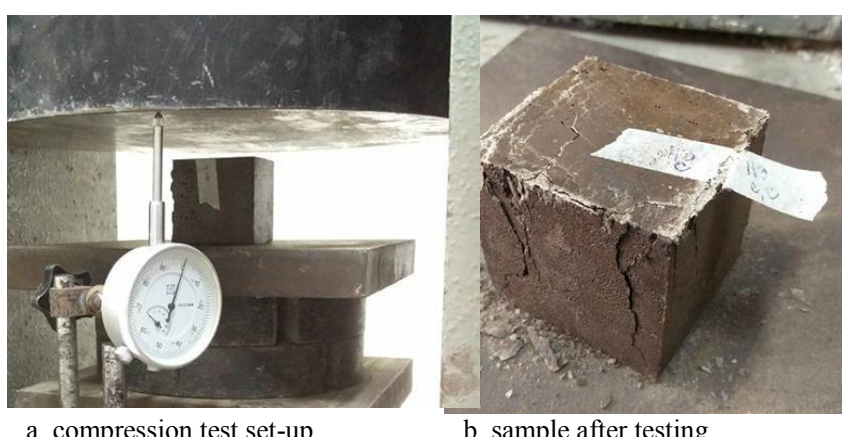

a. compression test set-up

b. sample after testing

Fig. 5. Compressive strength test set-up

The average of the compressive strengths of three specimens was taken as the measured value for each run. Pristine geopolymer samples (0\% fiber loading, $0 \%$ $\mathrm{H}_{2} \mathrm{O}_{2}$ dosage, cured at $52.5^{\circ} \mathrm{C}$ ) were measured to have a mean compressive strength of $24.04 \mathrm{MPa}$. The compressive strength values ranged from $19.56 \mathrm{MPa}$ to $36.85 \mathrm{MPa}$. The mean value is 29.26 MPa. Compressive strength requirements are at least $17 \mathrm{MPa}$ and $28 \mathrm{MPa}$ for residential and commercial concrete, respectively [24]. Compressive strength was analyzed as response to the three factors and a 2 nd degree model was generated. The measured $R^{2}$ is 0.8275 . Table 4 and summarizes the compressive strength data. Table 5 shows the ANOVA for compressive strength. 
Table 4. Compressive strength of the abaca-reinforced geopolymer composites

\begin{tabular}{|l|l|l|c|}
\hline \multicolumn{1}{|c|}{$\begin{array}{c}\text { Liber } \\
(\%)\end{array}$} & \multicolumn{1}{|c|}{$\begin{array}{c}\mathrm{H}_{2} \mathrm{O}_{2} \\
\text { Dosage } \\
(\%)\end{array}$} & $\begin{array}{c}\text { Curing } \\
\text { Temp. } \\
\left({ }^{\circ} \mathrm{C}\right)\end{array}$ & $\begin{array}{c}\text { Compressive } \\
\text { strength } \\
(\mathrm{MPa})\end{array}$ \\
\hline 0 & 0.16 & 52.5 & 27.58 \\
\hline 0 & 0.32 & 52.5 & 23.70 \\
\hline 0 & 0.24 & 30 & 21.54 \\
\hline 0 & 0.24 & 75 & 34.50 \\
\hline 0.25 & 0.16 & 30 & 24.96 \\
\hline 0.25 & 0.16 & 75 & 35.54 \\
\hline 0.25 & 0.32 & 30 & 28.46 \\
\hline 0.25 & 0.32 & 75 & 19.56 \\
\hline 0.25 & 0.24 & 52.5 & 32.25 \\
\hline 0.5 & 0.16 & 52.5 & 33.27 \\
\hline 0.5 & 0.32 & 52.5 & 30.97 \\
\hline 0.5 & 0.24 & 30 & 28.11 \\
\hline 0.5 & 0.24 & 75 & 34.27 \\
\hline$* 0$ & 0.24 & 75 & 2.23 \\
\hline$* 0.25$ & 0.32 & 30 & 1.82 \\
\hline$* 0.5$ & 0.16 & 52.5 & 2.96 \\
\hline$*$ replicated treatments & & \\
\hline
\end{tabular}

Table 5. Compressive strength summary of fit and Analysis of Variance

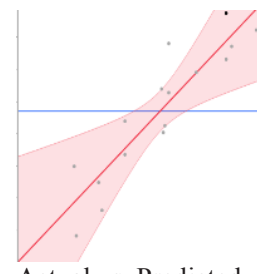

Actual vs. Predicted

\begin{tabular}{|l|l|l|l|l|}
\hline Source & DF & $\begin{array}{l}\text { Sum of } \\
\text { Squares }\end{array}$ & $\begin{array}{l}\text { Mean } \\
\text { Square }\end{array}$ & $\begin{array}{l}\text { F } \\
\text { Ratio }\end{array}$ \\
\hline Model & 7 & 342.15 & 48.8788 & 6.8917 \\
\hline Error & 8 & 56.74 & 7.0925 & $\begin{array}{l}\text { Prob }> \\
\text { F }\end{array}$ \\
\hline $\begin{array}{l}\text { C. } \\
\text { Total }\end{array}$ & 15 & 398.89 & & 0.0071 \\
\hline
\end{tabular}

Table 6 summarizes the parameter estimates of the model for compressive strength. The abaca reinforcement was found to have improved the compressive strength of the composites. This signifies that the fibers have sufficiently been treated and have formed an effective interaction with the matrix. Foaming agent dosage expectedly decreases compressive strength since more voids are expected to form. Higher curing temperature also improved the compressive strength. This agrees with previous reports [19]. It is said that heat curing facilitates in the reaction and formation of dense geopolymer matrix. The interaction between $\mathrm{H}_{2} \mathrm{O}_{2}$ dosage and curing temperature, however, resulted to weaker composites. As evidenced by the SEM images and qualitative results of preliminary preparation of samples, it is likely due to the microcrack formation when $\mathrm{H}_{2} \mathrm{O}_{2}$ dosage and curing temperature are simultaneously set at high levels.
Table 6. Compressive strength model parameter estimates

\begin{tabular}{|l|l|l|l|l|}
\hline Term & Estimate & Std Error & t Ratio & Prob $>|t|$ \\
\hline Intercept & 32.220605 & 1.723139 & 18.7 & $<.0001$ \\
\hline Fiber(0,0.5) & 2.5907439 & 0.899289 & 2.88 & $\mathbf{0 . 0 1 8 2}$ \\
\hline $\begin{array}{l}\mathrm{H} 2 \mathrm{O} 2(0.16, \\
0.32)\end{array}$ & -2.663281 & 0.901261 & -2.96 & $\mathbf{0 . 0 1 6 1}$ \\
\hline $\mathrm{CT}(30,75)$ & 2.7500156 & 0.901261 & 3.05 & $\mathbf{0 . 0 1 3 8}$ \\
\hline $\mathrm{H} 2 \mathrm{O} 2 * \mathrm{CT}$ & -4.752168 & 1.277011 & -3.72 & $\mathbf{0 . 0 0 4 8}$ \\
\hline
\end{tabular}

Fiber - \% Fiber Loading; $\mathrm{H} 2 \mathrm{O} 2-\% \mathrm{H}_{2} \mathrm{O}_{2}$ Dosage; CT - Curing Temperature ${ }^{\circ} \mathrm{C}$

\subsubsection{Flexural strength of geopolymer composites}

Flexural strength, which is also referred to as bend strength, is the mechanical property which measures the stress in the material right before it yields or deforms in a bending test. It is the highest stressed loaded to the material at point of failure. Foam concrete's flexural stress was typically measured to be in the range $15 \%$ to $35 \%$ of its own compressive strength [25]. Very few studies have considered this parameter. A specimen with

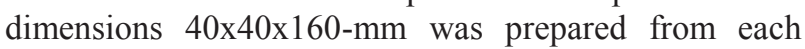
treatment for this test. The test was performed after 28 days of curing. Each sample was subjected to rate of load $0.3 \mathrm{MPa} / \mathrm{s}$; flexural strength was calculated following ASTM C348. Fig. 6 shows the set up for flexural test.

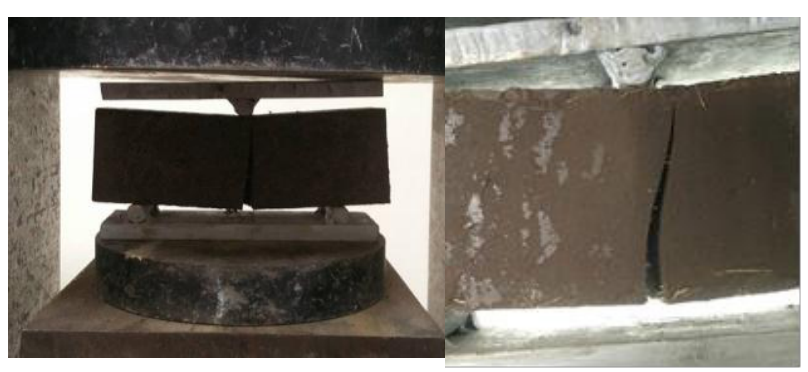

Fig. 6. Flexural strength test set-up

A pristine geopolymer sample ( $0 \%$ fiber loading, $0 \%$ $\mathrm{H}_{2} \mathrm{O}_{2}$ dosage, cured at $52.5^{\circ} \mathrm{C}$ ) was measured to have $5.81 \mathrm{MPa}$ flexural strength. As shown in Table 7, the flexural strength values ranged from $2.415 \mathrm{MPa}$ to 6.254 $\mathrm{MPa}$, with a mean value of $4.323 \mathrm{MPa}$. These values are in the same range as previous reports on geopolymer's flexural strength [26-27]. Table 7 summarizes the measured flexural strength for each treatment. 
Table 7. Flexural strength of the abaca-reinforced geopolymer composites

\begin{tabular}{|c|c|c|c|}
\hline $\begin{array}{c}\text { Fiber } \\
\text { Loading } \\
(\%)\end{array}$ & $\begin{array}{c}\mathrm{H}_{2} \mathrm{O}_{2} \\
\text { Dosage } \\
(\%)\end{array}$ & $\begin{array}{l}\text { Curing } \\
\text { Temp. } \\
\left({ }^{\circ} \mathrm{C}\right)\end{array}$ & $\begin{array}{c}\text { Flexural } \\
\text { Strength } \\
(\mathrm{MPa})\end{array}$ \\
\hline 0 & 0.16 & 52.5 & 6.25 \\
\hline 0 & 0.32 & 52.5 & 4.23 \\
\hline 0 & 0.24 & 30 & 5.39 \\
\hline 0 & 0.24 & 75 & 2.41 \\
\hline 0.25 & 0.16 & 30 & 5.18 \\
\hline 0.25 & 0.16 & 75 & 5.98 \\
\hline 0.25 & 0.32 & 30 & 3.70 \\
\hline 0.25 & 0.32 & 75 & 3.87 \\
\hline 0.25 & 0.24 & 52.5 & 4.95 \\
\hline 0.5 & 0.16 & 52.5 & 5.23 \\
\hline 0.5 & 0.32 & 52.5 & 3.84 \\
\hline 0.5 & 0.24 & 30 & 4.01 \\
\hline 0.5 & 0.24 & 75 & 2.82 \\
\hline$* 0$ & 0.24 & 75 & 2.51 \\
\hline$* 0.25$ & 0.32 & 30 & 3.64 \\
\hline$* 0.5$ & 0.16 & 52.5 & 5.13 \\
\hline
\end{tabular}

A second-degree model was fit with the data, and $\mathrm{R}^{2}=$ 0.5362 . The model itself was not very significant as shown in Table 8. The table summarizes the model's fit and ANOVA for flexural strength.

Table 8. Flexural strength summary of fit and Analysis of Variance

\begin{tabular}{|c|c|c|c|c|c|}
\cline { 2 - 6 } & Source & DF & $\begin{array}{c}\text { Sum of } \\
\text { Squares }\end{array}$ & $\begin{array}{c}\text { Mean } \\
\text { Square }\end{array}$ & $\begin{array}{c}\text { F } \\
\text { Ratio }\end{array}$ \\
\cline { 2 - 6 } & Model & 2 & 11.17650 & 5.58825 & 7.5135 \\
\cline { 2 - 6 } & Error & 13 & 9.668871 & 0.74376 & $\begin{array}{c}\text { Prob }> \\
\text { F }\end{array}$ \\
\cline { 2 - 6 } & $\begin{array}{c}\text { C. } \\
\text { Total }\end{array}$ & 15 & 20.84537 & & 0.0068 \\
\hline \multirow{2}{*}{ Actual vs. Predicted }
\end{tabular}

Among the factors, foaming agent dosage was found to be a significant factor, which expectedly caused flexural strength to decline due to formation of void spaces in the matrix. This relationship was observed from Table 9, which shows the parameter estimates of the model.

Table 9. Compressive strength model parameter estimates

\begin{tabular}{|c|c|c|c|c|}
\hline Term & Estimate & Std Error & $\begin{array}{c}\mathrm{t} \\
\text { Ratio }\end{array}$ & Prob $>|\mathrm{t}|$ \\
\hline Intercept & 3.6819481 & 0.352079 & 10.46 & $<.0001$ \\
\hline $\begin{array}{c}\mathrm{H} 2 \mathrm{O} 2 \\
(0.16,0.32)\end{array}$ & -0.850624 & 0.27272 & -3.12 & $\mathbf{0 . 0 0 8 1}$ \\
\hline $\mathrm{H} 2 \mathrm{O} 2 * \mathrm{H} 2 \mathrm{O} 2$ & 1.0251364 & 0.445349 & 2.3 & $\mathbf{0 . 0 3 8 5}$ \\
\hline
\end{tabular}

The negative coefficient associated with the first-degree factor $\mathrm{H} 2 \mathrm{O} 2$ (foaming agent dosage) signifies increasing $\mathrm{H}_{2} \mathrm{O}_{2}$ dosage results to lower flexural strength. However, the model generated has found significance in the second-degree factors of the $\mathrm{H}_{2} \mathrm{O}_{2}$ dosage. Intriguingly, the second-degree parameter was associated with a positive coefficient. This signifies that a curve exists and that the flexural strength can possibly increase at a threshold $\mathrm{H}_{2} \mathrm{O}_{2}$ dosage. The voids and pores formed from added foaming at an optimal or desired dose, can possibly serve as a "shock absorber" during impact. This could explain how foaming can improve flexural strength as suggested by the positive coefficient associated with this parameter.

In this study, the effect of natural fiber reinforcement to flexural strength remained inconclusive. Although statistical analysis presents no indication of any significant effect of fiber reinforcement to flexural strength, it was qualitatively observed that samples subjected to bending load were somehow held together by the fibers at the point of failure, as shown in Fig. 7.
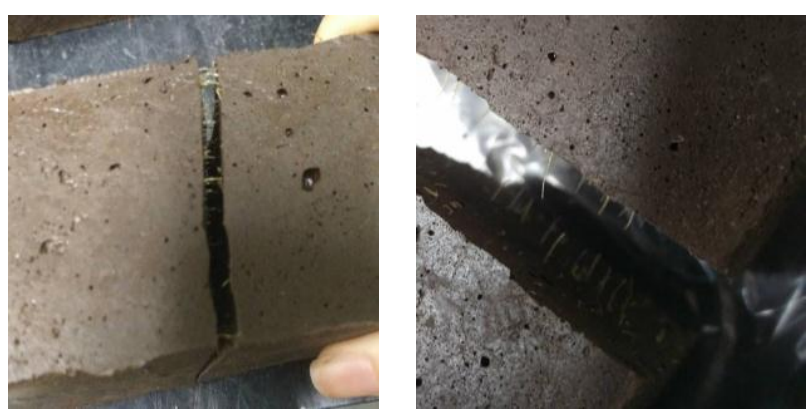

Fig. 7. Bridging fibers at composite's point of failure

\section{Conclusions}

Treated fibers appeared rougher and more uniform in SEM images; this, in theory, facilitated in interlocking of fiber with the matrix and could therefore enhance the composite's performance. The alkali treatment has sufficiently removed hydrophilic components and impurities as evidenced by TGA results and the lack of significance of fiber loading's effect on the composite's water absorption.

Compressive strength of the samples ranged from 19.56 $\mathrm{MPa}$ to $36.85 \mathrm{MPa}$. The mean value is $29.26 \mathrm{MPa}-$ comparable to the standards for residential and commercial structural concrete. Abaca reinforcement and heat curing both improved the compressive strength. Foaming resulted to weaker composites. The interaction of $\mathrm{H}_{2} \mathrm{O}_{2}$ dosage and curing temperature significantly affected compressive strength. Compressive strength declined when these factors are set at high levels at the same time due to microcrack formation as observed in the samples' SEM images. 
Flexural strength values ranged from $2.415 \mathrm{MPa}$ to 6.254 , with a mean value of $4.323 \mathrm{MPa}$. Addition of foaming agent was observed to weaken the composite's flexural strength, as expected. The correlation of the factors to flexural strength remains inconclusive due to the model's lack of fit. Fiber aggregation during the hardening period could have contributed to the experimental errors It was, however, qualitatively observed that the abaca fibers bridged across the point of failure during the performance of the flexural test.

\section{References}

1. L. Perez-Lombard, J. Ortiz, C. Pout. Energy Build. 40, 394-398 (2008)

2. Z. Zhang, J.L. Provis, A. Reid, H. Wang. Cem. Concr. Compos. 62, 97-105 (2015)

3. M.W. Ibrahim, N. Jamaludin, J. Irwan, P. Ramadhansyah, A.S. Hani. AMR. 911, 489-493 (2014)

4. S. Taj, M. Munawan, S. Khan. Proceedings of the Pakistan Academy of Sciences. 44(2), 129-144 (2007).

5. Philippine Statistics Authority. Selected Statistics on Agriculture 27, 13-18 (2016) Retrieved May 6, 2017, from https://psa.gov.ph/sites/default/files/Selected\%20Sta tistics\%20on\%20Agriculture\%202016.pdf

6. R. Dungani, M.S. Karina, A. Sulaeman, D. Hermawan, A. Hadiyane. Asian J. Plant Sci. 15(1), 42-55 (2016).

7. R. Araral. Turning Abaca Wastes Into Export Grade Handicraft (2004) Retrieved August 13, 2017, from http://sntpost.stii.dost.gov.ph/frames/OctToDec04/p g41_exportGradehandicraft.htm

8. C. Feliciano. Abaca shipments up nearly $40 \%$ by value in 11 months to November. (2015). Retrieved on August 13, 2017 from http://www.bworldonline.com/content.php?section= Economy\&title=abaca-shipments-up-nearly-40\%by-value-in-11-months-to-november \&id $=106608$

9. J. Arcalas. PHL abaca production grew $5.7 \%$ in 2016. (2017). Retrieved August 13, 2017 from http://www.businessmirror.com.ph/phl-abacaproduction-grew-5-7-in-2016/

10. E. Agung, S. Sapuan, M. Hamdan, H.D. Zaman, U. Mustofa. Int. J. Phys. Sci. 6(8), 2100-2106 (2011)

11. G. Islam, S. Gupta. Int. J. Sust. Built Environ. 5(2), 345-354 (2016)

12. P. Ramadevi, D. Sampathkumar, B. Bennehalli, P. Badyankal, S. Venkateshappa. Int. J. Chem. 35(2), 1699-1706 (2014)

13. O. Faruk, A. Bledzki, H. Fink, M. Sain. Prog. Polym. Sci. 37(11), 1552-1596 (2012)

14. P. Ramadevi, S. Venkateshappa, R. Sampathkumar, D. Bennehalli. Bioresour. 7(3), 3515-3524 (2012)
15. A. Jabbar, J. Militký, J. Wiener, M.U. Javaid, S. Rwawiire. Indian J. Fibre Text. Res. 41, 249-254 (2016)

16. O. Onuaguluchi, N. Banthia. Cem. Concr. Compos. 68, 96-108 (2016).

17. M. Cai, H. Takagi, A.N. Nakagaito, Y. Li, G.I. Waterhouse. Composites Part A. 90, 589-597 (2016)

18. M.M. Kabir, H. Aravinthan, H. Wang, T. Cardona, K.T. Lau. Energy, Environment and Sustainability. EddBE2011 Proceedings. 2011, 94-99 (2011)

19. J. Zhang, L. Feng, D. Wang, R. Zhang, G. Liu, G. Cheng. Bioresour. Technol. 153, 379-382 (2014)

20. V. Ducman, L. Korat. Mater. Charact. 113, 207-213 (2016)

21. G. Das, S. Biswas. Mater. Sci. Eng. 115(2016)

22. M. Abdullah, K. Hussin, M. Bnhussain, K. Ismail, Z. Yahya, R. Razak. Int. J. Mol. Sci. 13(2012)

23. M. Jones, A. Mccarthy. Fuel. 84(11), 1398-1409 (2005)

24. National Ready Mixed Concrete Association [NRMCA]. Concrete in Practice (2003). Retrieved June 29, 2017, from http://welschreadymix.com/wpcontent/uploads/2016/04/CIP35-

Testing_Compresive_Strength_of_Concrete.pdf

25. Y. Amran, N. Farzadnia, A.A. Ali. Constr. Build. Mater. 101, 990-1005 (2015)

26. K. Korniejenko, E. Frączek, E. Pytlak, M. Adamski. Procedia Engineering. 151, 388-393 (2016)

27. A. Bhutta, P.H. Borges, C. Zanotti, M. Farooq, N. Banthia. Cem. Concr. Compos. 80, 31-40 (2017) 